\title{
Hydrogenolysis of Birch Ethanol-Lignin in Supercritical Over Bifunctional Ru and Ni Catalysts Bifunctional Supported on Oxidized Carbon
}

\author{
Andrey S. Chikunov*a, Mikhail V. Shashkova, \\ Andrey V. Pestunov ${ }^{b}$, Aleksander S. Kazachenko ${ }^{b}$, \\ Tatyana I. Mishenko a and Oxana P. Taran ${ }^{\mathrm{a}, \mathrm{c}}$ \\ ${ }^{a}$ Boreskov Institute of Catalysis $S B R A S$ \\ 5 Lavrentieva, Novosibirsk, 630090, Russia \\ ${ }^{b}$ Institute of Chemistry and Chemical Technology SB RAS \\ FRC "Krasnoyarsk Science Center SB RAS" \\ 50/24 Akademgorodok, Krasnoyarsk, 660036, Russia \\ ${ }^{c}$ Novosibirsk State Technical University \\ 20 Karl Marx, Novosibirsk, 630073, Russia
}

Received 20.10.2017, received in revised form 17.11.2017, accepted 26.01.2018

Here we studied the process of catalytic hydrogenolysis of organosolvent birch wood lignin (Betula alba) in supercritical ethanol under soft conditions $-260{ }^{\circ} \mathrm{C}, 6-8 \mathrm{MPa}$. We use the nanoscale Ru and Ni metallic particles supported on oxidized carbon material Sibunit like bifunctional catalysts. We characterized the catalysts by TEM, N2 adsorption (BET), suspension $p H$. We analyze the liquid and gaseous reaction products by gas chromatography $(G C)$ and gas chromatography with mass spectrometry (GC-MS). We found that Ru- and Ni-contained catalysts increase the liquid products yields (significant increasing of yields of monomeric components) and prevent formation of gas and char. The maximal yield of products (81 wt. \%) was obtained in presence of catalyst contained $3 \mathrm{wt}$. $\%$ of Ru, moreover the monomer yield was $36 \%$. The use of carbon support with high concentration of acid sites allows us to enhance the process of lignin ethanolysis. The sametime we found that use of Ni catalysts leads to formation of C-C bond cracking products. The use of Ru catalysts results in formation of hydrogenation products.

Keywords: birch wood, lignin, hydrogenolysis, carbon catalysts.

Citation: Chikunov A.S., Shashkov M.V., Pestunov A.V., Kazachenko A.S., Mishenko T.I., Taran O.P. Hydrogenolysis of birch ethanol-lignin in supercritical ethanol over $\mathrm{Ru}$ and $\mathrm{Ni}$ catalysts bifunctional supported on oxidized carbon, J. Sib. Fed. Univ. Chem., 2018, 11(1), 131-150. DOI: 10.17516/1998-2836-0064.

(C) Siberian Federal University. All rights reserved

* Corresponding author E-mail address: chikunov@catalysis.ru 


\title{
Гидрогенолиз этаноллигнина березы \\ в среде сверхкритического этанола \\ в присутствии бифункциональных Ru- \\ и Ni-содержащих катализаторов, закрепленных \\ на окисленном углеродном носителе
}

\author{
А.С. Чикунов ${ }^{a}$, М.В. Шашков ${ }^{a}$, А.В. Пестунов \\ А.С. Казаченко \\ ${ }^{a}$ Институт катализа им. Г.К. Борескова СО РАН \\ Россия, 630090, Новосибирск, пр. Академика Лаврентьева, 5 \\ ${ }^{6}$ Институт химии и химической технологии СО РАН \\ ФИЦ «Красноярский научный центр СО РАН» \\ Россия, 660036, Красноярск, Академгородок, 50/24 \\ ${ }^{8}$ Новосибирский государственный технический университет \\ Россия, 630073, Новосибирск, пр. Карла Маркса, 20
}

Проведено исследование каталитического процесса гидрогенолиза органосольвентного лигнина березы белой (Betula alba) в среде сверхкритического этанола в присутствии бифункциональных катализаторов, содержащих наноразмерныеметаллические частищы $R u$ u $\mathrm{Ni}$, закрепленные на окисленном углеродном материале Сибунит. Приготовленные катализаторы изучены физико-химическими методами (ПЭМ, адсорбция N2, pH суспензии) и испьтаны в процессе гидрогенолиза вмягких условиях при $260^{\circ} \mathrm{C}, 6-8$ МПа. Составжидких игазообразных продуктов процесса гидрогенолиза анализировали методами ГХ и ГХ-МС. Обнаружено, что присутствие в реакционной среде катализаторов, содержащих металлические частищы Ru u Ni, приводит к увеличению выходов жидких продуктов (с ростом выходов мономеров) и уменьшению выходов газа и кокса. Максимальный выход жидких продуктов в присутствии катализатора, содержащего 3 мас. \% Ru, составил 81 мас. \%, из которых выход мономеров $36 \%$. Показано, что использование углеродного носителя с высокой концентрацией кислотных цеентров увеличивает выход продуктов этанолиза. Применение $\mathrm{Ni}$ - и Ru-содержащих катализаторов приводит к существенному увеличению выходов продуктов гидрогенолиза лигнина. Однако в присутствии Ni-катализаторов наблюдается образование продуктов крекинга $C$-C-связи алифатического заместителя, в то время как в присутствии Ru-катализатора наблюдаются продукты гидрирования.

Ключевые слова: древесина березы, лигнин, гидрогенолиз, углеродные катализаторы.

\section{Введение}

За последние пять лет во всем мире заметно интенсифицировались исследования, направленные на разработку процессов для комплексной переработки лигноцеллюлозной биомассы. 
Такой интерес вызван не только постепенным уменьшением запасов легко добываемых углеводородов, но и обострением экологических угроз, связанных с использованием традиционных ископаемых источников энергии и сырья. Биомасса растительного происхождения (лигноцеллюлоза), ежегодное образование которой в мире более 170 млрд т, является перспективным сырьем для замены ископаемых углеводородов. Лигноцеллюлоза представляет собой комплекс биополимеров сложного состава [1]. Основными структурными компонентами лигноцеллюлозной биомассы являются целлюлоза (40-50 \%), гемицеллюлозы (20-30 \%), лигнин (20-30 \%), экстрактивные вещества (3-4 \%) и минеральные компоненты ( 1 \%). Содержание этих компонентов может варьироваться в зависимости от вида растений [2]. На текущий момент только два (целлюлоза и гемицеллюлозы) из трех основных компонентов лигноцеллюлозного сырья перерабатываются в ценные продукты. Лигнин используют для приготовления пеллет и брикетов для сжигания либо просто складируют.

За последние годы появилось значительное число работ, в которых деполимеризацию лигнина проводили различными методами, например термохимическим способом либо ферментативной обработкой, а также каталитическими методами $[3,4]$. Большой интерес представляют процессы каталитического гидрогенолиза лигнина, так как данный подход позволяет в относительно мягких условиях получать ценные продукты в результате разрыва $\beta$-O-4-связи между единицами полимерного лигнина [5]. Деполимеризация лигнинов этим методом может проводиться в среде различных растворителей (например, вода, метанол, этанол, изопропанол, ацетон $[6,7])$ и в присутствии различных катализаторов (щелочи $(\mathrm{NaOH}, \mathrm{KOH})[8,9]$, а также катализаторов на основе переходных и благородных металлов, закрепленных на различных носителях (алюмосиликатах, углеродных материалах) $[10,11])$. Главным ограничением для применения процессов гидрогенолиза лигнина являются процессы реполимеризации и коксообразования, которые приводят не только к снижению конверсии, но и к дезактивации катализатора за счет образования на его поверхности инертного слоя кокса. Замедлить скорости этих нежелательных процессов можно, проводя процесс гидрогенолиза в среде сверхкритических растворителей [12].

Использование такого подхода позволило ряду авторов получить высокие выходы жидких продуктов. Например, в работе [13] щелочной лигнин марки Protobind перерабатывали в среде сверхкритического этанола в присутствии Cu/ZSM-5 катализаторов, содержащих различное количество $\mathrm{Cu}(5,10$ и 30 вес. \%) на цеолитах с различным модулем $(30,50,80,200)$, в атмосфере азота (10 бар) при $440{ }^{\circ} \mathrm{C}$. Для катализатора, содержащего $10 \%$ меди, на цеолите с модулем 30 выходы мономерных продуктов достигли 98,2 \%. Основными компонентами жидкой фазы оказались бензальдегид, м-ксилол, этилбензол и толуол, а увеличение кислотности носителя приводило к росту выходов мономерных продуктов. Подобное влияние содержания кислотных центров как для оксидных, так и для углеродных носителей описано в работе [14]. Однако проведение реакции гидрогенолиза при высоких температурах нежелательно из-за высоких энергетических затрат и уменьшения селективности. Поэтому усилия многих исследовательских групп направлены на поиск катализаторов, способных обеспечить приемлемый выход жидких продуктов в более мягких условиях $\left(\mathrm{T} \sim 240-260{ }^{\circ} \mathrm{C}\right)$.

Таким образом, разработка эффективных способов каталитической переработки лигнина методом гидрогенолиза в мягких условиях является весьма актуальной задачей, решение 
которой необходимо для разработки новых экологически безопасных ресурсосберегающих технологий получения ценных химических соединений и компонентов топлив. Несмотря на успехи в разработке каталитических методов гидрогенолиза, достигнутые за последние годы и представленные в литературе, у предложенных способов имеются весомые недостатки, к которым можно отнести необходимость проведения процесса при крайне высокой температуре (выше 340-440 ${ }^{\circ} \mathrm{C}$ ) для получения высоких выходов мономеров. Целью данной работы является разработка бифункциональных $\mathrm{Ru}-$ и $\mathrm{Ni}$-содержащих катализаторов на основе окисленного углеродного графитоподобного носителя Сибунит для процесса гидрогенолиза органосольвентного лигнина, а также установление взаимосвязей между природой активного металла, его содержанием, морфологией катализатора, а также выходами и составом продуктов.

\section{Материалы и методы}

Методы изучения состава лигнина

Лигнин получали из древесины березы белой (Betula alba) по методике, оптимизированной из $[15,16]$. Древесные опилки предварительно измельчали с помощью ударно-вихревой мельницы, разработанной в ИК СО РАН «ВМЭ-350» (Россия). Мощность вихревой мельницы 9 кВт; частота вращения ротора 9000 об/мин; диаметр разгоняющей материал вращающейся крыльчатки 0,27 м; скорость соударения материала с ударной поверхностью $140 \div 170 \mathrm{M} / \mathrm{c}$; объем помольной камеры составляет около $0,005 \mathrm{~m}^{3}$; расход воздуха через мельницу $650 \mathrm{~m}^{3} /$ ч. Для увеличения выхода лигнина (за счет набухания) древесину березы предварительно увлажняли до $22 \%$ и выдерживали при $20{ }^{\circ} \mathrm{C}$ в темноте в течение 48 ч. Далее 100 г разбухших опилок помещали в 1000 мл водно-этанольной смеси (этанол/вода в соотношении 60/40) и оставляли в темноте на 24 часа. Затем загружали полученную смесь в стальной реактор автоклава объемом 1500 мл и герметично его закупоривали (давление воздуха над жидкостью 1 атм), после чего реактор нагревали до $190{ }^{\circ} \mathrm{C}$. При данной температуре реакцию проводили 90 мин. Далее реактор охлаждали до комнатной температуры, полученный раствор от твердого остатка отделяли фильтрацией на фильтре белая лента и промывали водно-этанольной смесью (60/40) до обесцвечивания промывного раствора ( 500 мл). Фильтрат соединяли с промывными водами и охлаждали в холодильнике до $13^{\circ} \mathrm{C}$. Затем к раствору лигнина добавляли охлажденный водный раствор соляной кислоты с $\mathrm{pH} 1,5$, и оставляли на 24 ч в холодильнике $\left(13^{\circ} \mathrm{C}\right)$. Осажденный таким образом лигнин отделяли фильтрацией на ацетат-целлюлозном фильтре с диаметром пор 45 мкм, сушили при $35^{\circ} \mathrm{C}$ до постоянной массы.

Образец полученного лигнина был охарактеризован методом ИК-Фурье спектроскопии на спектрофотометре FTIR-8400S Shimadzu (Shimadzu, Япония). Регистрацию проводили в об-

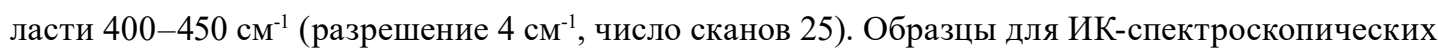
исследований готовили в виде таблеток с $\mathrm{KBr}$ в мольном соотношении 1:150.

Содержание сахаров в лигнине определяли после кислотного гидролиза двумя способами. Для трудногидролизуемых веществ воздушно-сухой образец лигнина 0,2 г помещали в 39 мл раствора $80 \%$-ной $\mathrm{H}_{2} \mathrm{SO}_{4}$ на 2,5 ч при комнатной температуре, затем разбавляли раствор до содержания $\mathrm{H}_{2} \mathrm{SO}_{4}$, равного 5 \% (суммарный объем 372 мл), и далее кипятили 5 ч. Для легкогидролизуемых веществ образец лигнина дважды обрабатывали $8 \%$-ной $\mathrm{H}_{2} \mathrm{SO}_{4}$ при $90{ }^{\circ} \mathrm{C}$ по 
2,5 ч [17]. Анализ гидролизатов осуществляли методом ВЭЖХ на хроматографе «МилихромА-02» (Милихром, Россия), оснащенном колонкой размером $2 \times 75$ мм, заполненной обращенофазовым сорбентом «Нуклеосил 5 - С18». Элюенты - вода и ацетонитрил с 0,1\%-м содержанием трифторуксусной кислоты. Гидролизаты лигнина предварительно дериватизировали 2,4-динитрофенилгидрозином в течение 90 мин при $65^{\circ} \mathrm{C}$.

\section{Приготовление и исследование катализаторов}

Углеродный носитель Сибунит-4 перед его модификацией по методике, описанной ранее [18], многократно промывали горячей дистиллированной водой для удаления возможных примесей металлов и нефтепродуктов. Далее носитель помещали в стеклянный реактор и сушили в токе аргона при $160{ }^{\circ} \mathrm{C}$ в течение 4 ч. Затем углеродный образец измельчали и отсеивали фракцию с размером частиц 56-96 мкм. Окисление углеродного образца «Сибунит-4» (15 г) проводили в течение 4 ч при $450{ }^{\circ} \mathrm{C}$ в токе искусственного воздуха $\left(\mathrm{O}_{2} / \mathrm{N}_{2}=1 / 5\right)$, насыщенного парами воды в сатураторе, термостатируемом при $90{ }^{\circ} \mathrm{C}$, с повторным продуванием образца аргоном в течение 30 мин [18].

Катализаторы, содержащие 1 и 3 \% рутения, готовили методом пропитки углеродного носителя по влагоемкости водным раствором нитразилнитрата рутения [19]. Влагоемкость окисленного Сибунита составила 1 мл/г. Для приготовления катализатора, содержащего 1 \% Ru, использовали 1\%-й раствор нитразилнитрата, для приготовления 3\%-го катализатора носитель дважды пропитывали 1,5\%-ным раствором комплекса с промежуточной сушкой. Образцы сушили при температуре $100{ }^{\circ} \mathrm{C}$ в течение 16 ч на воздухе. Затем высушенные предшественники катализатора загружали в стеклянный проточный реактор и продували током аргона в течение 30 мин со скоростью потока 12 мл/мин. Ток аргона меняли на ток водорода и начинали нагрев реактора со скоростью $1{ }^{\circ} \mathrm{C} /$ мин до $300{ }^{\circ} \mathrm{C}$. Восстановление рутения водородом производили при $300{ }^{\circ} \mathrm{C}$ в течение 120 мин. Затем реактор охлаждали, катализаторы пассивировали в токе газовой смеси $1 \%$ кислорода в азоте при комнатной температуре в течение 30 мин.

Никельсодержащий катализатор готовили методом пропитки углеродного носителя по влагоемкости из водного раствора нитрата никеля (II). Предшественник катализатора, как и в случае с рутением, сушили при $100{ }^{\circ} \mathrm{C}$ в течение 16 ч. Затем продували аргоном (скорость потока 12 мл/мин) в течение 30 мин, после чего ток аргона меняли на водород и начинали нагревание. Скорость нагрева $2{ }^{\circ} \mathrm{C}$ в мин (для 3 мас. \% Ni нагревали до 300 и $450{ }^{\circ} \mathrm{C}$, для 1 мас. \% Ni до $\left.450{ }^{\circ} \mathrm{C}\right)$. Восстановление проводили при соответствующей температуре в течение 120 мин. Охлаждение до комнатной температуры шло в атмосфере водорода, далее образцы никельсодержащих катализаторов хранили в атмосфе реаргона.

Текстурные характеристики образцов исследовали по изотермам адсорбции $\mathrm{N}_{2}$ при температуре минус $196{ }^{\circ} \mathrm{C}$ на установке ASAP-2400 (Micromeritics, США). Все образцы предварительно дегазировали в вакууме при температуре $150{ }^{\circ} \mathrm{C}$. Удельную площадь поверхности определяли при помощи классической модели БЕТ.

Кислотность носителя оценивали по значению $\mathrm{pH}$ суспензии, которую измеряли следующим образом: 0,5 г воздушно-сухого образца углеродного материала суспензировали в 10 мл дистиллированной воды (MilliporeMili-Q, удельное сопротивление 18 мОм/см) и продували аргоном со скоростью 10 мл/мин в течение 30 мин при постоянном перемешивании 
на магнитной мешалке. Затем пробирки закупоривали и следили за изменением $\mathrm{pH}$ (время с начала реакции $24,44,96,116$ ч) до установления равновесия. При каждом последующем измерении $\mathrm{pH}$ растворы повторно отдувались аргоном в течение 10 мин. Электронные снимки высокого разрешения и распределение частиц рутения по размерам для Ni- и Ru-содержащих катализаторов получали с помощью просвечивающего электронного микроскопа JEM-2010 (Япония) с ускоряющим напряжением 200 кВ и разрешением $1.4 \AA$. Гистограммы распределения частиц по размерам получали с применением статистической (200-500 частиц) обработки микрофотографий. Значения среднестатистического линейного $\left(<\mathrm{d}_{1}>\right)$ диаметра нанесенных частиц рассчитывали по формуле $<\mathrm{d}_{1}>=\Sigma \mathrm{d}_{\mathrm{i}} / \mathrm{N}$, где $\mathrm{d}_{\mathrm{i}}-$ диаметр нанесенной частицы; $\mathrm{N}$ - общее число частиц [20].

Проведение реакиии каталитического гидрогенолиза лигнина

в среде сверхкритического этанола и анализ продуктов реакиии

Процесс гидрогенолиза лигнина проводили при $260{ }^{\circ} \mathrm{C}$, давлении 6-8 МПа и постоянном перемешивании 900 об/мин с помощью магнитной мешалки в течение 6 ч в стальном реакторе (саль 12Х18Н10T) общим объемом 150 мл. В реактор загружали 45 мл этанола, 500 мг лигнина, 250 мг катализатора и 0,5 МПа аргона. Реактор герметизировали, трижды продували аргоном, нагревали до нужной температуры. По завершении процесса реактор охлаждали до комнатной температуры, проводили отбор газовой фазы для ее анализа методом газовой хроматографии, выгружали полученную смесь из реактора. Осадок от жидкости отделяли фильтрацией через воронку Бюхнера с ацетатцеллюлозным фильтром с размером пор 20 мкм. Осадок промывали несколько раз горячим этанолом до тех пор, пока раствор не становился бесцветным. Твердый осадок сушили в сушильном шкафу при температуре $(120 \pm 3)^{\circ} \mathrm{C}$ до постоянной массы. Полученную после промывки жидкость соединяли с раствором, отделенным после фильтрации, доводили до объема 100 мл. Из полученного раствора отбирали аликвотную часть 1 мл для исследования состава жидких продуктов методом ГХ-МС. Выход жидких продуктов определяли весовым методом после удаления растворителя на ротационном вакуумном испарителе Laborota-4000 (Heidolph, Германия) при $40{ }^{\circ} \mathrm{C}$.

Анализ газов проводили на газовом хроматографе «Кристалл 2000 М» («Хроматек», Россия) с пламенно-ионизационным детектором и колонкой Хромосорб 102 ( 2 м $\times 2$ мм). В качестве газа-носителя использовали аргон (расход 12 мл/мин). Температура детектора устанавливалась $200{ }^{\circ} \mathrm{C}$, испарителя $-150{ }^{\circ} \mathrm{C}$, колонки $-60^{\circ} \mathrm{C}$.

Состав жидкой фракции анализировали методом ГХ-МС на приборе Agilent 7000 В (США) с использованием колонки VF-5ms30 м $\times 0,25$ мм $\times 0,25$ мкм. Образцы предварительно силилировали, для чего 1 мл раствора упаривали досуха, затем добавляли 100 мкл пиридина и 100 мкл BSTFA. Вводили 10 мкг внутреннего стандарта (ионол) и выдерживали в течение часа при температуре $70{ }^{\circ} \mathrm{C}$. Условия разделения: программирование температуры осуществляли со скоростью $8{ }^{\circ} \mathrm{C} /$ мин от 80 до $300{ }^{\circ} \mathrm{C}$; скорость потока газа-носителя (гелий) 1,2 мл/мин; температура испарителя $300{ }^{\circ} \mathrm{C}$; объем пробы 3 мкл; сброс с испарителя 1:5. Идентификацию компонентов проводили по библиотеке масс-спектров NIST'11. Количество олигомеров определяли по разнице между массой всех жидких продуктов собщим количеством ароматических мономеров. 


\section{Результаты и обсуждения}

\section{Состав лигнина}

В качестве субстрата для испытания приготовленных катализаторов использовали этаноллигнин, приготовленный методом органосольвентной варки из древесины березы белой, предварительно измельченной с помощью ударно-вихревой мельницы, разработанной в ИК СО РАН. Размер частиц древесины, определенный методом оптической микроскопии, составлял (22 \pm 13$)$ мкм.

Химический состав полученного лигнина изучали методами ИК-спектроскопии и ВЭЖХ с предварительным гидролизом. На рис. 1 представлен ИК-Фурье спектр образца этаноллигнина. Интерпретация в соответствии с литературными данными [21] свидетельствует о том, что полученный спектр этаноллигнина березы содержит полосы, характерные для соединений лигнина. Полосы поглощения при частотах 1738-1707 см-1 соответствуют валентным колебаниям $\mathrm{C}=\mathrm{O}$ в неконъюгированных кетонах, карбонилах и в сложноэфирных группах (часто углеводных остатков). Конъюгированные альдегиды и карбоновые кислоты поглощают при 1605-1593 см-1 эта частота соответствует C-С-валентным колебаниям ароматического кольца и $\mathrm{C}=\mathrm{O}$-валентным колебаниям. Поглощение при $1515-1505 \mathrm{~cm}^{-1}$ характеризует $\mathrm{C}-\mathrm{C}$-валентные

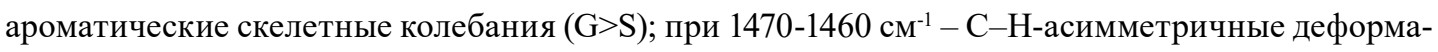
ционные колебания в метильных и метиленовых группах; при 1430-1422 см-1 - C-С-валентные ароматические скелетные колебания, а также С-Н-асимметричные плоскостные деформационные колебания в метоксильных группах; при 1325-1330 см-1 - скелетные колебания сирингильного кольца и колебания конденсированного гваяцильного кольца (т.е. гваяцильное кольцо, замещенное в 5-м положении); при 1230-1221 см-1 - скелетные колебания сирингильного кольца и С-О-валентные колебания в фенолах; при 1128-1124 см-1 - ароматические С-Н плоскостные деформационные колебания (типичны для сирингильных звеньев) и С-О-валентные колебания во вторичных спиртах, а также $\mathrm{C}-\mathrm{O}-\mathrm{C}$-асимметричные валентные колебания; при 1035-1030 см ${ }^{-1}$ - ароматические $\mathrm{C}-\mathrm{H}$ плоскостные деформационные колебания $(\mathrm{G}>\mathrm{S})$ и $\mathrm{C}-\mathrm{O}$ ва-

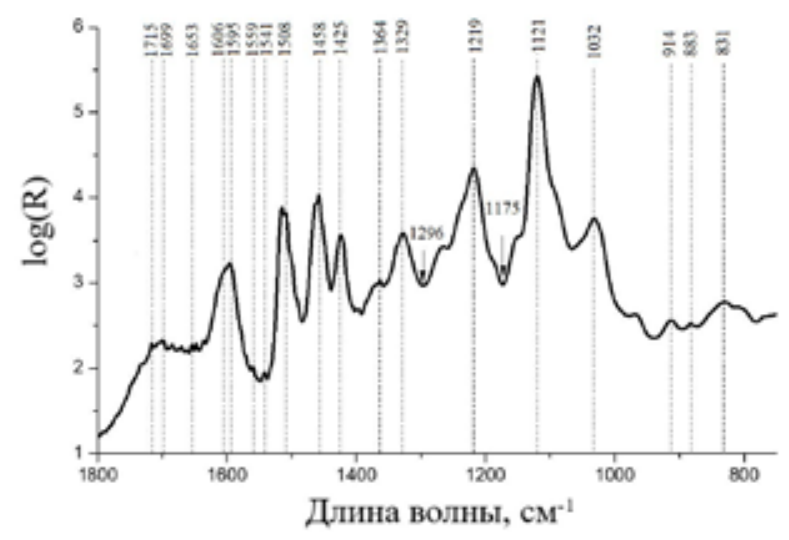

Рис. 1. ИК-Фурье спектр лигнина, полученного из опилок. Условия органосольвентной варки: загрузка обессмоленной биомассы 10 г, растворитель смесь вода-этанол $40 / 60$ об. \%, 90 мин, $\mathrm{P}_{\text {Аг }}^{0} 1 \mathrm{MПа,} 190{ }^{\circ} \mathrm{C}$

Fig. 1. FTIR spectrum of birch wood ethanol lignin. The conditions of organosolvent process: biomass load $10 \mathrm{~g}$, solvent water/ethanol in ratio $40 / 60$ vol. $\%, 90 \mathrm{~min}, \mathrm{P}^{0}{ }_{\mathrm{Ar}} 1 \mathrm{MPa}, 190{ }^{\circ} \mathrm{C}$ 
лентные колебания в первичных спиртах, а также $\mathrm{C}-\mathrm{O}-\mathrm{C}$ (неконъюгированные) симметричные валентные колебания; при 925-915 см-1 - C-Н-внеплоскостные деформационные колебания в ароматическом кольце; при 880-850 см-1 - C-Н-внеплоскостные деформационные колебания в положениях 2, 5 и 6 гваяцильного кольца; при 835-833 см-1 - C-Н-внеплоскостные деформационные колебания в положениях 2 и 6 сирингильного кольца и во всех положениях гидроксиароматических звеньев; при 832-817 - C-Н-внеплоскостные деформационные колебания в положениях 2, 5 и 6 гваяцильного кольца. Сопоставление интенсивностей полос, характерных для мономерных единиц - сирингола (наличие полос 1329 и 1219 см$^{-1}$, отвечающих валентным колебаниям связи С-О в сиринголе, а не 1270, 1230 и $1130 \mathrm{~cm}^{-1}$, характерных для С-О в гваяциле, также полоса внеплоскостного колебания водорода при $831 \mathrm{~cm}^{-1}$, характерная для сирингола, а не две при 880-850 и 855-800 см-1 для гваяцила), явно указывает на преимущественное присутствие в образце березового лигнина производных сирингола. Существенной интенсивности полос, характерных для углеводов, на спектре не наблюдается.

Проведение полного гидролиза образца этанол-лигнина березы в присутствии 80 \% $\mathrm{H}_{2} \mathrm{SO}_{4}$ с последующим определением сахаров методом ВЭЖХ выявило присутствие в образце 0,4 мас. \% галактозы и 5,9 мас. \% глюкозы. Анализ гидролизатов, полученных при обработке

$8 \%$-м раствором $\mathrm{H}_{2} \mathrm{SO}_{4}$, выявил присутствие в образце лигнина 0,1 мас. \% галактозы, 0,3 мас. \% глюкозы, 0,1 мас. \% маннозы, 0,1 мас. \% арабинозы и 0,9 мас. \% ксилозы. Суммарно полученные результаты указывают на низкое содержание сахаров в полученном лигнине - менее 7,5 мас. \%.

\section{Физико-химические свойства катализаторов}

В качестве носителя для катализаторов был выбран углеродный материал Сибунит 4 (S4). Ранее было обнаружено существенное увеличение выходов жидких продуктов и уменьшение выходов кокса при деполимеризации этаноллигнина в присутствии окисленного влажным воздухом Сибунита-4 (S4-O20) [14]. Для увеличения содержания кислотных групп на поверхности носителя в данной работе по методике, описанной в [18], окисляли предварительно механически измельченные гранулы Сибунита. Полученный таким образом носитель обозначен S4O20-MA.

Текстуру носителей исследовали методом низкотемпературной адсорбции азота, а кислотные свойства - методом измерения рН суспензии (табл. 1). Отметим, что исследования, проведенные в работе [18], показали, что значения $\mathrm{pH}$ суспензии для Сибунита-4, окисленного разными окислителями и при разных условиях, хорошо коррелируют с рН нулевого заряда и находятся в обратной корреляции с количеством кислотных групп на поверхности. Предварительное механическое измельчение углеродного материала Сибунит позволило избежать небольшого снижения общей площади поверхности, а также объема и диаметра пор носителя, в отличие от носителя SibS4-O20, использовавшегося в [14]. Вместе с тем значение $\mathrm{pH}$ суспензии полученного образца S4-O20-MA снизилось с 8,4 (для S4-O20) до 6,5 (для S4-O20-MA), что позволяет говорить о значительном увеличении количества поверхностных кислотных групп.

Морфология и текстура металлсодержащих катализаторов изучены методами низкотемпературной адсорбции азота и просвечивающей электронной микроскопии (ПЭМ) (табл. 2). Для катализатора, содержащего 3 мас. \% никеля, текстурные характеристики изменились наи- 
Таблица 1. Текстурные характеристики и значение $\mathrm{pH}$ водной суспензии для образцов носителя Сибунит

Table 1. Texture characteristics and aqueous suspension $\mathrm{pH}$ for samples of Sibunit supports

\begin{tabular}{|l|c|c|c|c|}
\hline \multirow{2}{*}{ Носитель } & \multirow{2}{*}{$\mathrm{S}_{\mathrm{BET}}, \mathrm{M}^{2} / \Gamma$} & \multicolumn{2}{|c|}{ Поры } & \multirow{2}{*}{ рН суспензии } \\
\cline { 3 - 5 } & & Объем, $\mathrm{cm}^{3} / \Gamma$ & Диаметр, нм & \\
\hline $\mathrm{S} 4$ & 379 & 0,63 & 6,6 & 9,4 \\
\hline $\mathrm{S} 4-\mathrm{O} 20$ & 348 & 0,44 & 5,1 & 8,4 \\
\hline $\mathrm{S} 4-\mathrm{O} 20-\mathrm{MA}$ & 374 & 0,52 & 5,5 & 6,5 \\
\hline
\end{tabular}

Таблица 2. Текстурные характеристики и средний размер частиц металла для Ru- и Ni-содержащих катализаторов

Table 2. Texture characteristics and average particle size of supported metal for Ru and Ni catalysts

\begin{tabular}{|c|c|c|c|c|}
\hline \multirow{2}{*}{ Образец } & \multirow{2}{*}{$\mathrm{S}_{\mathrm{BET}}, \mathrm{M}^{2} / \Gamma$} & \multicolumn{2}{|c|}{ Поры } & \multirow{2}{*}{$\begin{array}{c}\text { Размер } \\
\text { частиц }<\mathrm{d}>\text {, нм }\end{array}$} \\
\hline & & Объем, $\mathrm{cm}^{3} / \Gamma$ & Диаметр, нм & \\
\hline $1 \% \mathrm{Ru} / \mathrm{S} 4-\mathrm{O} 20-\mathrm{MA}$ & 368 & 0,54 & 5,9 & 1,0 \\
\hline $3 \% \mathrm{Ru} / \mathrm{S} 4-\mathrm{O} 20-\mathrm{MA}$ & 371 & 0,53 & 5,7 & 0,7 \\
\hline $1 \% \mathrm{Ni} / \mathrm{S} 4-\mathrm{O} 20-\mathrm{MA}$ & 365 & 0,53 & 5,8 & 7,3 \\
\hline $3 \% \mathrm{Ni} / \mathrm{S} 4-\mathrm{O} 20-\mathrm{MA}-450$ & 334 & 0,61 & 7,2 & 7,5 \\
\hline $3 \% \mathrm{Ni} / \mathrm{S} 4-\mathrm{O} 20-\mathrm{MA}-300$ & H.o. & H.о. & H.о. & 4,5 \\
\hline
\end{tabular}

более существенно. Так, общая площадь поверхности образцов заметно снизилась до $334 \mathrm{~m}^{2} / \Gamma$. Объем пор и их диаметр увеличились до $0,61 \mathrm{~cm}^{3} / \Gamma$ и 7,2 нм соответственно. Такое поведение может являться следствием разрушения поверхности углеродного носителя из-за воздействия высокой температуры при восстановлении никеля $\left(450{ }^{\circ} \mathrm{C}\right.$ для Ni по сравнению с $300^{\circ} \mathrm{C}$ для Ru). Нанесение 1 \% Ni либо 1, 3 мас. \% Ru не привело к значительным изменениям текстурных характеристик: площадь поверхности изменилась незначительно от 374 для исходного носителя до 365-371 м²/г. Общий объем пор также остался практически неизменным (0,52 для носителя; 0,53-0,54 см³/г для катализаторов). Средний диаметр пор увеличивается с 5,5 для исходного до 5,7-5,9 нм для катализаторов.

Анализ снимков, полученных методом просвечивающей электронной микроскопии, показал, что в случае катализатора, содержащего 3 мас. \% Ni при $300{ }^{\circ} \mathrm{C}$ (рис. $2 A$ ), восстановления активного компонента до состояния металлического никеля не произошло. На снимках наблюдаются частицы оксида никеля (II) со средним размером частиц 4.5 нм, распределенные равномерно по поверхности носителя. Поэтому температура восстановления в токе водорода была увеличена до $450{ }^{\circ} \mathrm{C}$ (рис. 2Б), как в работе [22]. На снимках катализаторов, содержащих 3 мас. \% $\mathrm{Ni}$, восстановленных при $450{ }^{\circ} \mathrm{C}$ (рис. $2 Б$ ), видны частицы металлического никеля округлой формы, равномерно распределенные по поверхности носителя. Средний диаметр частиц никеля составил 7,5 нм. На снимке катализатора, содержащего 1 мас. \% Ni (рис. 2B), никель наблюдается в виде металлических частиц округлой формы со средним размером 7,3 нм. Хранение данных катализаторов на воздухе в течение 48 ч приводило к образованию тонкой

$$
-139-
$$




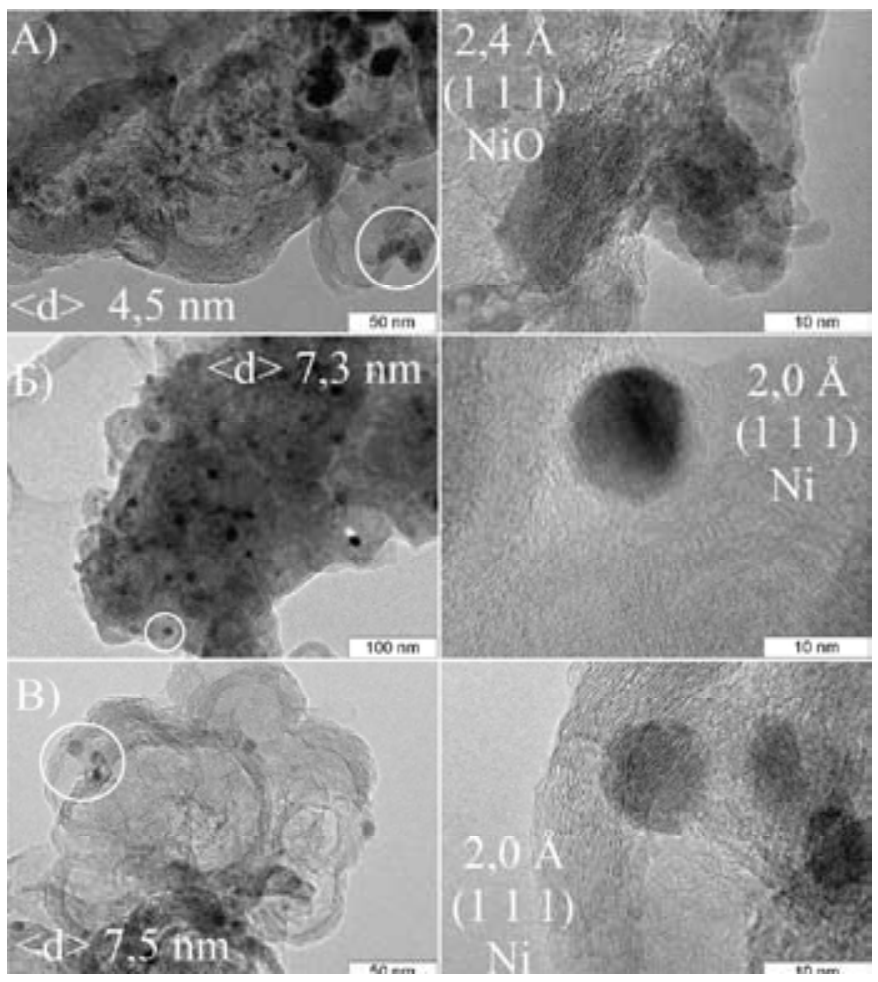

Рис. 2. Изображения Ni-содержащих катализаторов, полученные методом просвечивающей электронной микроскопии: A - 3\% Ni/S4-O20-MA-300; Б - 3\% Ni/S4-O20-MA-450; B - 1\% Ni /S4-O20-MA

Fig. 2. The TEM images of Ni catalysts. Left to right: A - 3\% Ni/S4-O20-MA-300; Б - 3\% Ni/S4-O20-MA-450; $\mathrm{B}-1 \% \mathrm{Ni} / \mathrm{S} 4-\mathrm{O} 20-\mathrm{MA}$

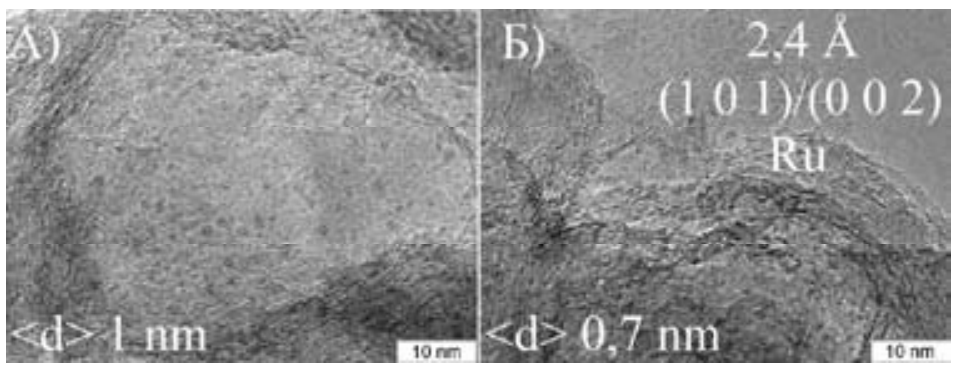

Рис. 3. Изображения Ru-содержащих катализаторов, полученные методом просвечивающей электронной микроскопии: A - 1\% Ru/Sib 4-O20-MA; Б - 3\% Ru/Sib 4-O20-MA

Fig. 3. The TEM images of Ru catalysts. Left to right: A - 1\% Ru/Sib 4-O20-MA; Б - 3\% Ru/Sib 4-O20-MA

пленки оксида никеля частицах (толщина около 0,5 нм) на поверхности металлических частиц, поэтому катализаторы хранили в атмосфере аргона.

Электронномикроскопические снимки катализаторов, содержащих 1 и 3 мас. \% Ru представлены на рис. $3 A$ и $E$, соответственно. В этих катализаторах частицы металлического рутения равномерно распределены по поверхности носителя. Увеличение количества окисленных групп, находящихся на поверхности носителя, привело к уменьшению среднего размера ча- 
стиц рутения с 1,5 (в случае с носителем S4-O20) нм до 0,7 нм для носителя S4-O20-MA. Нанесение меньшего количества рутения 1 мас. \% Ru из более разбавленного раствора привело к увеличению среднего размера частиц до 1 нм, что может объясняться частичным гидролизом предшественника (нитрозилнитратного комплекса рутения) с образованием полиядерных комплексов при разбавлении [23].

Таким образом, в процессе восстановления катализаторов при высоких температурах в токе водорода не происходит значительной деградации углеродного носителя, благодаря чему получены Ni- и Ru-содержащие катализаторы, обладающие развитой поверхностью и графитоподобной структурой, характерной для углеродного носителя Сибунит. Металлические компоненты катализаторов присутствуют в виде высокодисперсных металлических частиц, а носитель характеризуется высокой кислотностью за счет более глубокого окисления.

\section{Каталитический гидрогенолиз этаноллигнина}

в среде сверхкритического этанола

Целевым продуктом исследуемого процесса являются жидкие углеводороды, которые представляют собой смесь ценных моно- и олигомерных производных сирингольных, гваяцильных и гидроксифенольных компонентов лигнинов и потенциально могут быть использованы как сырье для получения ценных химических веществ, высокооктановых топливных добавок, полимеров. Образование кокса в результате реполимеризации лигнина крайне нежелательный побочный процесс, который не только снижает выходы целевых жидких продуктов, но и является причиной дезактивации катализаторов вследствие их зауглероживания и блокировки активных центров. В подобных процессах также наблюдалось образование газообразных продуктов (метана и оксидов углерода) [3-6]. Несмотря на то что подобная газовая смесь может быть использована для получения синтезгаза, наиболее ценным продуктом является жидкая фракция.

Нами проведены испытания окисленного углеродного носителя и всех приготовленных катализаторов. Фазовое распределение продуктов гидрогенолиза этаноллигнина березы, полученное в ходе испытаний катализаторов, приведено на рис. 4. Газовая фаза во всех экспериментах состояла преимущественно из метана с примесями ди- и монооксида углерода.

В условиях без катализатора процесс гидрогенолиза протекает с низкой эффективностью, о чем свидетельствует образование большого количества кокса (36,6 мас. \%). Газообразные продукты представлены метаном (5,6 мас. \%), моно- и двуокисью углерода (0,1 и 0,3 мас. \% соответственно). В жидкой фазе осталось 52 мас. \% продуктов реакции, которые представлены в основном ди- и олигомерами лигнина.

Введение в реакционную среду катализатора, содержащего частицы $\mathrm{Ni}$ в форме оксида (3 \% Ni/S4-O20-MА-300), привело к снижению выхода кокса до 14 мас. \% и незначительному увеличению выхода газовых компонентов до 7,9 мас. \%, при этом существенно увеличился выход жидких продуктов до 66 мас. \%. В присутствии катализатора, содержащего 3 мас. \% $\mathrm{Ni}$, восстановленного при $450{ }^{\circ} \mathrm{C}$, количество образующегося в ходе реакции кокса составило 14,4 \%, а процесс газообразования замедлился - суммарный выход газов составил 3,5 мас. \%. В жидкой фазе осталось существенное количество продуктов (72 мас. \%). Использование катализатора, содержащего 1 мас. \% Ni, восстановленного при $450{ }^{\circ} \mathrm{C}(1 \% \mathrm{Ni} / \mathrm{S} 4-\mathrm{O} 20-\mathrm{MA})$, привело 


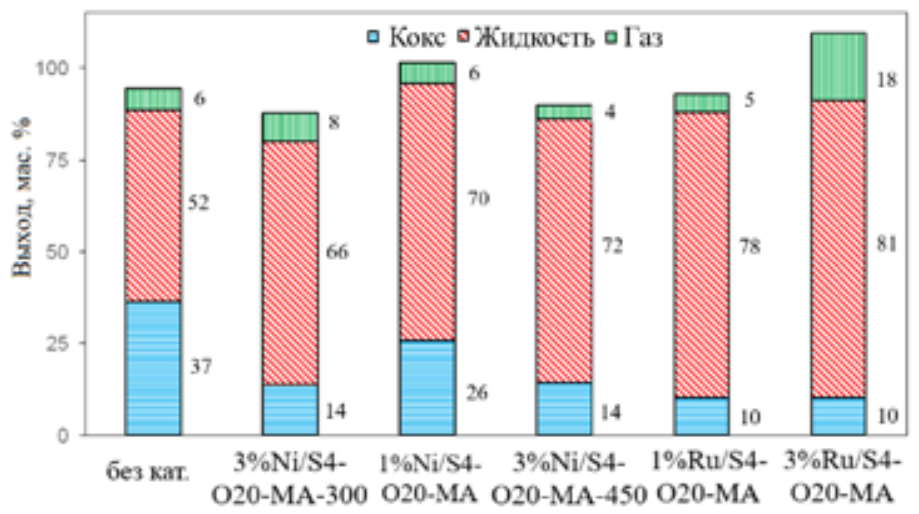

Рис. 4. Распределение продуктов каталитической деполимеризации этаноллигнина березы

Fig. 4. The distribution of products of catalytic depolymerization of birch wood ethanol lignin

к образованию существенного количества кокса 25,8 мас. \%. Выход газов несколько выше, чем в случае катализатора, содержащего 3 мас. \% Ni- 5,9 мас. \% (3 \% Ni/S4-O20-MA-450), выход жидких продуктов остался высоким (70 мас. \%).

Применение Ru-содержащих катализаторов приводит к еще большему увеличению выхода жидких продуктов и снижению выходов кокса. Количество кокса, образующегося в присутствии катализатора, содержащего 1 мас. \% Ru (1 \%Ru/S4-O20-MA), снизилось до 10,2 мас. \%, количество выделяющегося газа - до 4,9 мас. \%, в растворе осталось 78 мас. \% продуктов. Повышение содержания активного компонента до 3 мас. \% (3 \%Ru/S4-O20-MA) привело к высоким выходам газов (18,4 мас. \%) с преобладанием метана (6,2 мас. \%) и монооксида углерода (10,1 мас. \%). Количество образующегося кокса существенно не изменилось (10,3 мас. \%). Общий выход жидких продуктов увеличился до 84 мас. \%, что является лучшим результатом.

Таким образом, использование катализаторов, содержащих никель или рутений, позволяет значительно уменьшить коксо- и газообразование, при этом достигаются значительные выходы жидких продуктов (70-80 мас. \%). Наибольшую эффективность показали катализаторы $3 \% \mathrm{Ni} / \mathrm{S} 4-\mathrm{O} 20-\mathrm{MA}-450$ и $1 \% \mathrm{Ru} / \mathrm{S} 4-\mathrm{O} 20-\mathrm{MA}$.

\section{Анализ состава жидкой фракции методом ГХ-МС}

Количественный анализ состава жидких продуктов реакции проводили методом ГХ-МС с применением в качестве внутреннего стандарта ионола - представителя класса фенолов, не встречающегося в природе в чистом виде (табл. 3). Расчет массовых выходов отдельных веществ проводили за вычетом вклада силанольных групп в суммарную массу силилированных производных, значения даны в процентах от общего количества жидких продуктов реакции.

В экспериментах без использования катализатора основными мономерными продуктами гидрогенолиза этаноллигнина березы оказались производные сирингола: сирингол $(4,2 \%)$, п-метилсирингол $(1,9 \%)$, п-этилсирингол $(1,0 \%)$ и п-пропилсирингол $(0,9 \%)$; и гваякола: гваякол $(0,8 \%)$ и п-этилгваякол $(0,5 \%)$. Появление в составе продуктов соединений с укороченным алифатическим фрагментом, очевидно, вызвано термическим крекингом пропановых фрагментов фенилпропаноидных субъединиц лигнина [24]. Суммарный выход продуктов с кис- 
Таблица 3. Состав основных жидких продуктов каталитического гидрогенолиза лигнина согласно данным ГХ-МС (приведены только результаты, превышающие 0,8 мас. \%). Значения указаны в процентах от в мас. \% от жидкой фракции

Table 3. Distribution of products in liquid phase after catalytic hydrogenolysis of lignin. GC/MS data (only results exceeding 0.8 wt. $\%$ are shown). Values wt. $\%$ of total liquid products

\begin{tabular}{|c|c|c|c|c|c|c|c|}
\hline \multirow[b]{2}{*}{ Соединение } & \multirow[b]{2}{*}{ Структура } & \multicolumn{6}{|c|}{ Катализатор } \\
\hline & & без кат. & 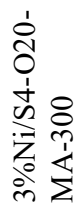 & 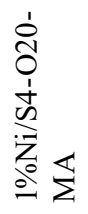 & 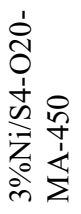 & 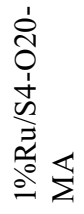 & 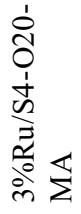 \\
\hline 1 & 2 & 3 & 4 & 5 & 6 & 7 & 8 \\
\hline Гваякол & & 0,8 & 0,8 & 0,9 & 0,8 & 0,6 & 0,7 \\
\hline п-Метилгваякол & & 0,3 & 0,3 & 0,8 & 0,7 & 0,6 & 0,9 \\
\hline п-Этилгваякол & & 0,5 & 0,5 & 0,7 & 0,9 & 0,8 & 1,4 \\
\hline п-Пропилгваякол & & 0,3 & 0,3 & 0,7 & 0,8 & 2,5 & 4,1 \\
\hline п-Аллилгваякол & & 0,1 & 0,9 & 1,0 & 1,4 & 1,9 & 0,5 \\
\hline Конифериловый спирт & & 0,1 & 0,1 & 0,8 & 0,5 & 0,4 & 0,3 \\
\hline Сирингол & & 4,2 & 3,7 & 2,8 & 2,7 & 1,9 & 2,4 \\
\hline п-Метилсирингол & & 1,9 & 2,1 & 3,8 & 3,4 & 2,8 & 2,5 \\
\hline
\end{tabular}


Продолжение таблицы 3

Continued Table 3

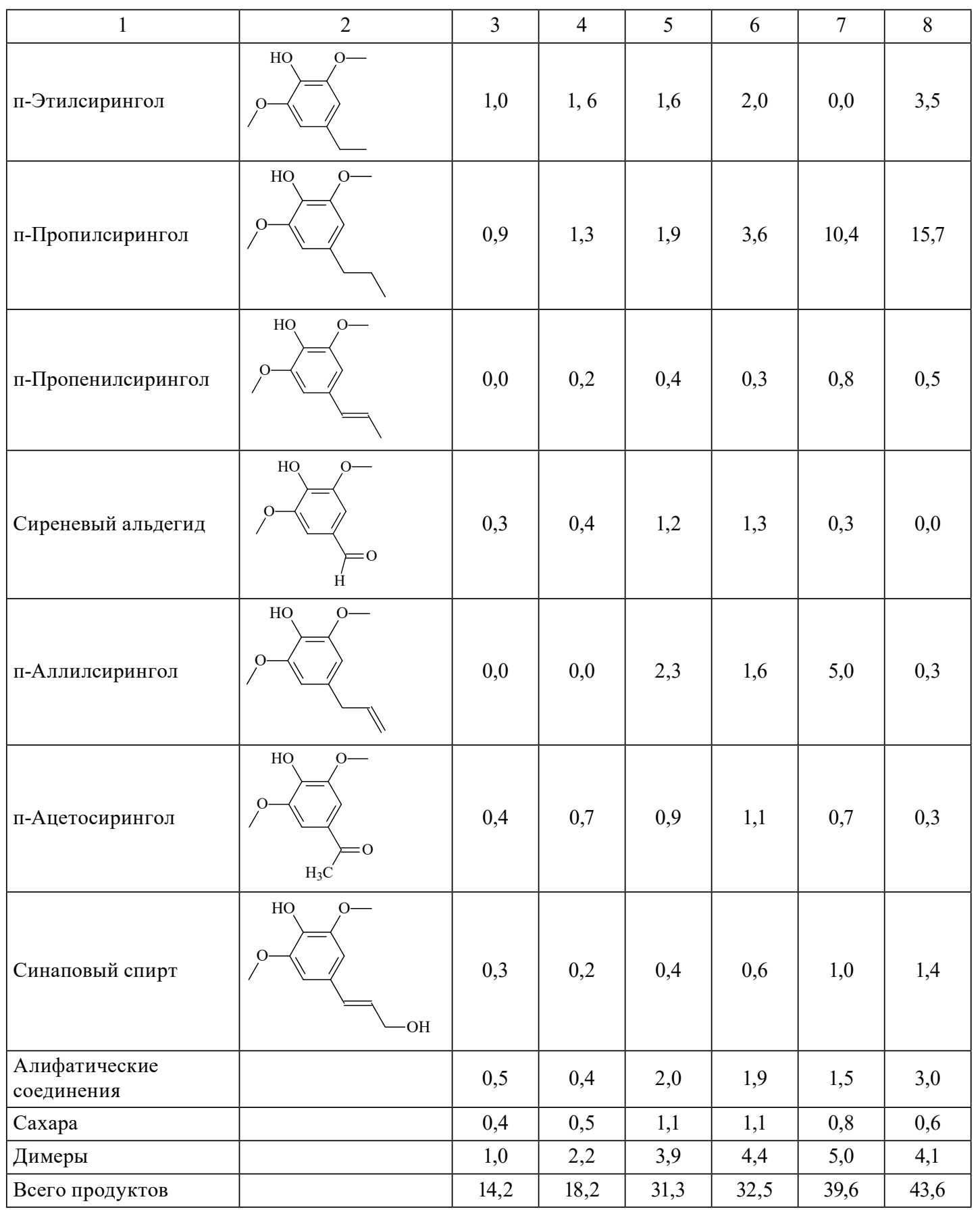

лородсодержащими заместителями (оксигенатов) составил 1,9 \% (рис. 5). Идентифицированы: ванилин, сиреневый альдегид, п-ацетогваякол, п-ацетосирингол, а также дигидроферуловая кислота и синаповый спирт, выходы каждого составили примерно 0,1-0,3%. Данные соеди- 


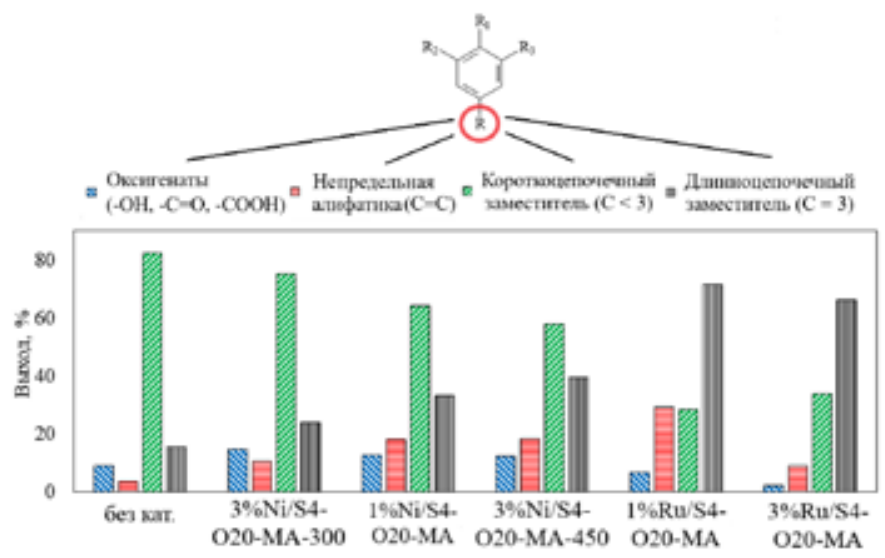

Рис. 5. Распределение ароматических продуктов гидрогенолиза лигнина, полученных в присутствии различных катализаторов, отличных по содержанию функциональных групп в алифатическом заместителе - R (оксигенаты, включающие группы -OH, -C=O, -COOH; непредельные алифатические заместители (содержат $\mathrm{C}=\mathrm{C}$ ); короткоцепочечные заместители, содержащие меньше трех атомов углерода; длинноцепочечные заместители, содержащие три атома углерода)

Fig. 5. The distribution of aromatic products of lignin hydrogenolysis over various catalysts, differing by functional groups in aliphatic substituent $-\mathrm{R}$ (oxygenates which include $-\mathrm{OH},-\mathrm{C}=\mathrm{O}$, $-\mathrm{COOH}$; unsaturated aliphatic substituents (contain $\mathrm{C}=\mathrm{C}$ ); short-chain substituents contained less than three carbon atoms; long-chain substituents which contained three carbon atoms)

нения могут появляться в реакционной смеси в результате как этанолиза лигнина, так и окисления его фрагментов в ходе выделения методом органосольвентной варки [25]. Обнаружено небольшое количество алифатических соединений $-0,4 \%$, в основном это гликолевая кислота $(0,2 \%)$ и глицерин $(0,1 \%)$. Кроме того, зарегистрированы незначительные количества димеров лигнина (1\%), идентифицированы: $\beta-1$ ' гваяцил-гваяцил $(0,4 \%)$, гваяцил-сирингил $(0,2 \%)$ и 5-5' гваяцил-гваяцил $(0,6$ \%). Зарегистрированы невысокие выходы сахаров - 0,4 \%. Общий выход идентифицированных продуктов составил 14,2 \%, что свидетельствует о невысокой скорости термического процесса гидрогенолиза в выбранных условиях.

Применение катализатора, содержащего 3 мас. \% $\mathrm{Ni}$, восстановленного при $300{ }^{\circ} \mathrm{C}(3 \%$ $\mathrm{Ni} / \mathrm{S} 4-\mathrm{O} 20-\mathrm{MA-300),привело} \mathrm{к} \mathrm{изменению} \mathrm{количественного} \mathrm{состава} \mathrm{мономерных} \mathrm{продуктов:}$ сирингол (3,7 \%), п-метилсирингол (2,1 \%), п-этилсирингол (1,6 \%) и п-пропилсирингол $(1,3 \%)$, а также гваякол $(0,8 \%)$, п-метилгваякол (0,3 \%), п-этилгваякол $(0,5$ \%) и п-пропилгваякол $(0,3 \%)$. Тем не менее соотношение выходов продуктов оказалось подобным соотношению в эксперименте без катализатора (рис. 5), что указывает на существенный вклад процесса крекинга алифатического заместителя. Появление в составе продуктов таких соединений, как ванилиновая кислота $(0,4$ \%) и сиреневая кислота $(0,1 \%)$, п-аллилгваякол $(0,9 \%)$ и п-изоаллилгваякол $(0,2$ \%), указывает на увеличение вклада процессов этанолиза макромолекул лигнина на кислых центрах углеродного носителя. Подобный эффект наблюдался в работе [26] при использовании катализатора $\mathrm{Pd} / \mathrm{C}$ и кислотного сокатализатора. Суммарное количество оксигенатов составило $2,8 \%$. Количество обнаруженных алифатических компонентов не увеличилось, а количество димеров лигнина возросло до $2,2 \%$, причем идентифицирован новый продукт: $\beta$ - $\beta$-гваяцилсирингил $(0,4$ \%). Общее количество регистрируемых продуктов после применения катализа- 
тора увеличилось до 18,2 \%, что, по-видимому, в большей степени обусловлено кислотными свойствами углеродного носителя Сибунит.

В эксперименте в присутствии катализатора, содержащего 1 мас. \% $\mathrm{Ni}$, восстановленного при $450{ }^{\circ} \mathrm{C}(1 \% \mathrm{Ni} / \mathrm{S} 4-\mathrm{O} 20-\mathrm{MA})$, качественный состав жидких продуктов существенно изменился в направлении увеличения выходов продуктов с длинноцепочечным алифатическим заместителем (15,6 \% продуктов с коротко- и 7,8 \% с длинноцепочечными заместителями (рис. 5)). Так, выходы производных сирингола составили: сирингол (2,8 \%), п-метилсирингол $(3,8$ \%), п-этилсирингол (1,6 \%) и п-пропилсирингол $(1,3 \%)$; гваякола: гваякол $(0,9 \%)$, п-метилгваякол $(0,8 \%)$, п-этилгваякол $(0,7 \%)$ и п-пропилгваякол $(0,7 \%)$. Выход оксигенатов увеличился до $5,4 \%$. Кроме того, увеличились выходы соединений, содержащих ненасыщенные алифатические заместители до 4,8 \% (п-аллилгваякол (1 \%), п-пропенилгваякол $(0,3)$, п-аллилсирингол (2,3\%), п-пропенилсирингол $(0,4 \%))$, следовательно, в присутствии данного катализатора интенсифицируются не только этанолиз, но и гидрогенолиз. Вслед за увеличением выходов ароматических соединений возросли выходы (до 2,1 \%) алифатических соединений, в основном это гликолевая кислота $(0,6 \%)$, этиленгликоль $(0,5 \%)$, бутан-2,3-диол $(0,7 \%)$ и глицерин (0,3. \%). Выход димеров лигнина также увеличился до 3,9 \%. Все вышеперечисленные факты свидетельствуют о интенсификации процессов гидрогенолиза в присутствии частиц металлического $\mathrm{Ni}$.

Увеличение содержания Ni в катализаторе до 3 мас. \% (3 \% Ni/S4-O20-MA-450) привело к еще большему перераспределению состава жидких продуктов в сторону увеличения содержания продуктов с длинноцепочечными заместителями (15 коротко- и 9,6 \% длинноцепочечных заместителей). Основные продукты: сирингол (2,7 \%), п-метилсирингол $(3,4 \%)$, п-этилсирингол (2 \%), п- пропилсирингол (3,6 \%), гваякол $(0,8 \%)$, п-метилгваякол $(0,7$ \%), п-этилгваякол $(0,9 \%)$ и п-пропилгваякол $(0,7 \%)$. Выход оксигенатов $(5,3 \%)$ и продуктов, содержащих ненасыщенные алифатические заместители (4,3\%), не увеличился, причем происходит перераспределение образующихся продуктов в сторону более длинноцепочечных - синапового и кониферилового спиртов (0,6 и 0,5 \% соответственно). Количество высвободившихся алифатических продуктов практически не изменилось $(1,9 \%)$, эти продукты представленны в основном гликолевой кислотой $(0,8 \%)$ и бутан-2,3-диолом $(0,6)$. Вслед за общим увеличением выходов образующихся жидких продуктов увеличился выход детектируемых димеров лигнина (3,9 \%). Увеличение выходов продуктов гидрогенолиза по сравнению с продуктами крекинга указывает на эффективность катализаторов, содержащих металлический никель, в данном процессе.

Смена активного компонента c Ni на Ru привела к еще большему увеличению вклада процесса гидрогенолиза в распределение продуктов (рис. 5). Хотя возможной причиной более высокой активности рутениевых катализаторов является их более высокая дисперсность, при условии повышения дисперсности никеля на поверхности катализатора приведет к улучшению каталитических свойств. В присутствии катализатора, содержащего $1 \% \mathrm{Ru}$, основными продуктами оказались п-пропилсирингол (10,4 \%), п-аллилсирингол (5 \%), п-метилсирингол (2,8 \%), сирингол (1,9 \%), п-пропилгваякол $(2,5 \%)$ и п-аллилгваякол $(1,9 \%)$. Выходы оксигенатов также снизились до 4,5 \%, по-видимому, в результате процесса гидрирования на металлическом катализаторе. Зарегистрировано еще больше продуктов с ненасыщенной алифатической частью (8,5 \%), причем основными продуктами стали п-аллилсирингол $(5$ \%) и 
п-аллилгваякол (1,9 \%). Выход продуктов с длинноцепочечным заместителем $(23,2$ \%) превышает короткоцепочечные (9 \%) более чем в 2 раза. Образующиеся алифатические продукты составляют 1,4 \% от общего количества жидких продуктов. Наблюдаемое перераспределение продуктов указывает на превалирование процессов гидрогенолиза в присутствии $\mathrm{Ru}$-содержащего катализатора.

Увеличение содержания Ru до 3 мас. \% позволило еще больше увеличить скорость процесса гидрогенолиза по сравнению со скоростями процессов крекинга алифатической части монолигнинолов и этанолиза лигнина. Так, основными продуктами оказались п-пропилгваякол $(4,1 \%)$ и п-пропилсирингол (15,7 \%). Количество оксигенатов в растворе снизилось до 3,2 \%, а соединений, содержащих ненасыщенные алифатические заместители, до 1,6 \%. Выход длинноцепочечных продуктов составляет 23,3 \% против 12,4 \% для короткоцепочечных. Образуется максимальное количество свободной аллифатики (2,9\%), причем в основном это бутандиолы. Наблюдается и снижение количества димеров - до 4,1 мас. \%. Следовательно, увеличение количества рутения привело к увеличению не только скорости гидрогенолиза, но и гидрирования оксигенатов и двойных связей. Аналогичный эффект наблюдался в [27], когда увеличение количества $\mathrm{Pd} / \mathrm{C}$ катализатора относительно добавки кислотного сокатализатора приводило к снижению выходов оксигенатов.

Таким образом, при использовании катализаторов, содержащих 1 и 3 мас. \% активного компонента для $\mathrm{Ni}$ и $\mathrm{Ru}$, получены суммарные выходы ароматических мономерных продуктов: 23,$4 ; 24,6 ; 32,2$ и 35,7 \%. Продукты можно разделить на четыре группы: 1) соединения, алифатические фрагменты которых имеют короткоцепочечные заместители и содержащие меньше трех атомов углерода в цепи, являющиеся продуктами крекинга лигнина и монолигнолов (незамещенные и п-метил- и п-этилзамещенные фенол, гваякол и сирингол); 2) продукты этанолиза полимеров лигнина, образующиеся на кислых центрах носителя, - оксигенаты $[28,29]$ (п-ацетогваякол, п-ацетосирингол, сиреневый альдегид, ванилин, бензойная, кумариновая, ванилиновая и гомованилиновая кислота, дигидроферуловая и сиреневая кислоты, а также метилгидрохинон, пирокатехол и пирогалол); 3) соединения, содержащие ненасыщенные алифатические заместители, - продукты гидрогенолиза на металлических центрах катализаторов (п-пропенилгваякол, п-аллилгваякол, конифериновый спирт, п-пропенилсирингол, п-аллилсирингол и синаповый спирт); 4) продукты гидрирования соединений третьей группы - вещества, содержащие алкильные заместители, в которых количество атомов углерода равно трем (п-пропил-, п-аллил- и п-пропенилзамещенные гваякол и сирингол, а также соответсвующие спирты - синаповый, конифериловый, дигидроконифериловый). Анализ представленной на рис. 4 диаграммы распределения продуктов по этим четырем группам позволяет заключить, что с повышением эффективности металлического катализатора значительно снижаются выходы оксигенатов и увеличиваются продукты гидрогенолиза и гидролиза.

\section{Заключение}

Разработаны катализаторы, содержащие наноразмерные частицы Ru и Ni (1 и 3 мас \%), закрепленные на сильно окисленный углеродный носитель Сибунит, для гидрогенолиза лигнина. Использование сильно окисленного носителя позволило достичь существенного увеличения выходов жидких продуктов до 81 мас. \% в случае катализатора, содержащего 3 \% Ru, из

$$
-147-
$$


которых 35,7 \% это мономерные фрагменты лигнина. Для катализатора, содержащего $3 \% \mathrm{Ni}$, также достигнут высокий выход жидких продуктов (72 \%), из которых 24,6 \% мономеры. Таким образом, результат, полученный на $\mathrm{Ni}$-содержащем катализаторе, незначительно уступает результату в присутствии Ru-содержащего катализатора, что создает перспективы разработки процесса гидрогенолиза лигнина на более дешевом никелевом катализаторе. Основными образующимися газами являются метан и монооксид углерода.

Исследование состава жидких продуктов реакции методом ГХ-МС выявило присутствие в реакционной смеси мономерных и димерных фрагментов лигнина в качестве основных продуктов, а также сахаров и алифатических кислородсодержащих производных в качестве примесей. Мономерные ароматические продукты разделяются на четыре группы в соответствии с химической природой алифатического заместителя в пара-положении и, следовательно, с маршрутом выделения из полимерного лигнина. Во-первых, это продукты термического крекинга (соединения без заместителя и с короткоцепочеными заместителями); во-вторых, продукты этанолиза, происходящего на кислотных центрах носителя (оксигенаты); в-третьих, продукты гидрогенолиза на металлических центрах (соединения с аллильными и спиртовыми заместителями); в-четвертых, продукты гидрирования и деоксигенации соединений из двух предыдущих групп. Увеличение кислотности носителя смещает распределение продуктов процесса в сторону соединений второй группы, а увеличение количества металла и его дисперсности - в сторону соединений третьей и четвертой групп.

Полученные в результате каталитического гидрогенолиза лигнина ароматические мономеры (пара-аллилсирингол, пара-пропилсирингол, пара-пропилгваякол и др.) являются ценным сырьем для химической и фармацевтической отраслей промышленности, а также могут в перспективе быть использованы для производства полимеров и топливных присадок.

\section{Благодарности}

Работа выполнена при поддержке РАН и ФАНО России (проект V. 47.1.12). Авторы благодарят к.Х.н. В.Н. Панченко за помощь в регистрации и интерпретации ИК- спектров.

\section{Список литературы}

1. Kamm B., Gruber P.R., Kamm M. Biorefineries Industrial Processes and Products. WileyVCH. Weinheim 2006. Vol. 2. P. 1-40.

2. Lennartsson P.R., Niklasson C., Taherzadeh M.J. A pilot study on lignocelluloses to ethanol and fish feed using NMMO pretreatment and cultivation with zygomycetes in an air-lift reactor. Bioresource Technology 2011. Vol. 102(6), P. 4425-4432.

3. Pandey M.P., Armbruster U., Richter M., Martin A. Lignin depolymerization and conversion: A review of termochemical methods. Chem. Eng. Technol. 2011. Vol. 34(1), P. 29-41.

4. Wang H., Tucker M.P., Ji Y. Recent development in chemical depolymerization of lignin: A review. J. Chem. Technol. Biot. 2013. Vol. 86(1), P. 1-9.

5. Xu C., Arancon R.A., Labidi J., Luque R. Lignin depolymerisation strategies: towards valuable chemicals and fuels.Chem. Soc. Rev. 2014. Vol. 43(22), P. 7485-7500.

6. Wahyudiono, Sasaki M., Goto M. Recovery of phenolic compounds through the decomposition of lignin in near and supercritical water.Chem. Eng. Process. 2008. Vol. 47, P. 1609-1619. 
7. Warner G., Hansen T.S., Riisager A., Beach E.S., Barta K., Anastas P.T. Depolymerization of organosolv lignin using doped porous metal oxides in supercritical methanol. Bioresour. Technol. 2014. Vol. 161, P. 78-83.

8. Roberts V.M., Stein V., Reiner T., Lemonidou A., Li X., Lercher J.A. Towards quantitative catalytic lignin depolymerization. Chem. Eur. J. 2011. Vol. 17, P. 5939-5948.

9. Hidajat M.J., Riaz A., Park J., Insyani R., Verma D., Kim J. Depolymerization of concentrated sulfuric acid hydrolysis lignin to high-yield aromatic monomers in basic sub- and supercritical fluids. Chem. Eng. J. 2017. Vol. 317, P. 9-19.

10. Deepa A.K., Dhepe P.L. Lignin depolymerization into aromatic monomers over solid acid catalysts. ACS Catal. 2015. Vol. 5, P. 365-379.

11. Onwudili Jude A., Williams P.T. Catalytic depolymerization of alkali lignin in subcritical water: influence of formic acid and $\mathrm{Pd} / \mathrm{C}$ catalyst on the yields of liquid monomeric aromatic products. Green Chem. 2014. Vol. 16, P. 4740.

12. Guo D., Liu B., Tang Y., Zhang J., Xia X., Tong S. Catalytic depolymerization of alkali lignin in sub- and super-critical etanol. Bio Resources 2017. Vol. 12(3), P. 5001-5016.

13. Jeong S., Yang S., Kim D.H. Depolymerization of Protobind lignin to produce monoaromatic compounds over Cu/ZSM-5 catalyst in supercritical ethanol. J. Mol. Cat. 2017. Vol. 442, P. 140-146.

14. Аюшеев А.Б., Афиногенова И.И., Мищенко Т.И., Шашков М.В., Сашкина К.А., Семейкина В.С., Пархомчук Е.В., Таран О.П. Деполимеризация органосольвентного лигнина березы в среде сверхкритического этанола в присутствии твердых катализаторов. Журнал Сибирского федерального университета. Химия. 2016. № 3, С. 353-370. [Ayusheev A.B., Afinogenova I.I., Mishchenko T.I., Shashkov M.V., Sashkina K.A., Semeikinaa V.S., Parkhomchuk E.V., Taran O.P. Depolymerization of Birch-Wood Organosolv Lignin Over Solid Catalystsin Supercritical Ethanol. Journal of Siberian Federal University. Chemistry 2016. Vol. 3, P. 353-370 (In Russ.)]

15. Чикунов А.С., Афиногенова И.И., Аюшеев А.Б., Есипчук М.А., Таран О.П. Влияние условий органосольвентной варки биомассы березы на выходы и свойства этаноллигнина. Вестн. Том. гос. ун-та. Химия 2017. № 9, С. 35-49. [Chikunov A.S., Afinogenova I.I., Esipchuk M.A., Taran O.P. Influence of conditions of organosolvent cooking of birch biomass on yields and properties of ethanol-lignin. Tomsk State University Journal of Chemistry 2017. Vol. 9, P. 35-49 (In Russ.)]

16. Quesada-Medina J., López-Cremades F.J., Olivares-Carrillo P. Organosolvextractionoflig ninfromhydrolyzedalmondshellsandapplicationofthed-valuetheory. Bioresource Technology 2010. Vol. 101, P. 8252-8260.

17. Оболенская А.В., Ельницкая 3.П., Леонович А.А. Лабороторные работы по химии древесины и целлюлозы. Москва: Экология, 1991. С. 366. [Obolenskaya A.V., Elnitskaya Z.P., Lenovich A.A. Laboratory work on the chemistry of wood and cellulose. Moscow: Ecology, 1991. P. 366 (In Russ.)]

18. Таран О.П., Полянская Е.М., Огородникова О.Л., Descorme Claude, Besson Michèle, Пармон В.Н. Катализаторы на основе углеродного материала Сибунит для глубокого окисления органических экотоксикантов в водных растворах. (1). Свойства поверхности окисленного Сибунита. Катализ в промышленности 2010. № 6, С. 48-54. [Taran O.P., Polyanskaya E.M., Ogorodnikova O.L., Descorme C., Besson M., Parmon V. Sibunit-based catalytic materials for the deep 
oxidation of organic ecotoxicants in aqueous solution: I. Surface properties of the oxidized Sibunit samples. Catal. Ind. 2010. Vol. 2(4), P. 381-386 (InRuss.)]

19. Таран О.П., Descorme С., Полянская Е.М., Аюшеев А.Б., Besson М., Пармон В.Н. Катализаторы на основе углеродного материала «Сибунит» для глубокого окисления органических экотоксикантов в водных растворах. (3) Аэробное окисление фенола в присутствии окисленных углеродных и Ru/C катализаторов. Катализ в промышленности 2013. Т. 13(1), С. 40-50. [Taran O.P., Descorme C. Polyanskaya E.M., Ayusheev A.B., Besson M., Parmon V.N. Oxidation of Organic Ecotoxicants in Aqueous Solutions. III: Wet Air Oxidation of Phenol over Oxidized Carbon and Ru/C Catalysts. CatalysisinIndustry 2013. Vol. 5(2), P. 164-174 (In Russ.)]

20. Андерсон Дж. Структура металлических катализаторов. М.: Мир, 1978. С. 482. [Anderson J.R., Structureofmetallic catalysts. M.: Mir, 1978. P. 482 (In Russ.)]

21. Базарнова Н.Г., Карпова Е.В. и др. Методы исследования древесины и ее производных. Барнаул: Изд-во Алт. гос. ун-та, 2002. 160 с. [Bazarnova N.G., Karpova E.V. Methods of studying wood and its derivatives. Barnaul: Publishing of Altay State University, 2002. P. 160 (In Russ.)]

22. Song Q., Wang F., Cai J., Wang Y., Zhang J., Yu W., Xu J. Lignin depolymerization (LDP) in alcohol over nickel-based catalysts via a fragmentation-hydrogenolysis process. Energ. \& Env. Sci. 2013. Vol. 3, P. 994-1007.

23. Jenkins I.L., Wain A.G., The proton dissociation and hydrolysis in trinitratonitrosylruthenium in aqueous solutions. J. Inorg. And Nucl. Chem. 1956. Vol. 3, P. 28-37.

24. Yoshikawa T., Yagi T., Shinohara S., Fukunaga T., Nakasaka Y., Tago T., Masuda T. Production of phenols from lignin via depolymerization and catalytic cracking. Fuel Proc. Technol. 2013. Vol. 108, P. 69-75.

25. Roberts V.M., Stein V., Reiner T., Lemonidou A., Li. D.X., Lercher J.A. Towardsquantitative catalyticlignindepolymerization. Cem. Eur. J. 2011. Vol. 17, P. 5939-5948.

26. Huang X., Gonzalez O.M.M., Zhu J., Koranyi T.I., Boot M.D., Hensen E.J.M. Reductive fractionation of woody biomass into lignin monomers and cellulose by tandem metal triflate and $\mathrm{Pd} / \mathrm{C}$ catalysis. Green. Chem. 2017. Vol. 19, P. 175.

27. Huang X., Ouyang X., Hendriks B.M.S., Gonzalez O.M.M., Zhu J., Koranyi T.I., Boot D.M., Hensen E.J.M. Selective production of mono-aromatics from lignocellulose over Pd/C catalyst: the influence of acid co-catalysts. Faraday Discuss. 2017. Vol. 202, P. 141-156.

28. Azadfar M., Gao A.H., Bule M.V., Chen S. Structural characterization of lignin: a potential source of antioxidants guaicol and 4-vinylguaiacol. Int. Jour. Bio. Macromolecules 2015. Vol. 75, P. 58-66.

29. Peleg H., Naim M., Zehavi U., Rouseff R.L., Nagyl S. Pethways of 4-Vinylguaicol Formation from Ferulic acid in model solutions of orange juice. J. Agric. Food. Chem. 1992. Vol. 40, P. 764-767. 